\title{
Simulation of Cardiovascular Diseases Using Electronic Circuits
}

\author{
DG Tsalikakis $^{1,2}$, DI Fotiadis ${ }^{1,2,3}$, D Sideris T $^{3,4}$ \\ ${ }^{1}$ Unit of Medical Technology and Intelligent Information Systems, Dept. of Computer Science, \\ University of Ioannina, GR 45110 Ioannina, Greece \\ ${ }^{2}$ Biomedical Research Institute-FORTH, GR 45110 Ioannina, Greece \\ ${ }^{3}$ Michaelidion Cardiology Center, GR 45110 Ioannina, Greece \\ ${ }^{4}$ Division of Cardiology, Medical School, University of Ioannina, GR 45110 Ioannina, Greece
}

\begin{abstract}
We have developed an electronic circuit to simulate the behavior of the cardiovascular system under normal or pathological conditions. The current, voltage, charge, resistance and capacitance of the circuit correspond to flow, blood pressure, volume, resistance and capacitance of the simulated cardiovascular system, respectively. We have implemented a circuit with two ventricles separated from the systemic and the pulmonary circulation to simulate normal conditions. Vital parameters of the cardiovascular system such as aortic pressure, cardiac output, end-diastolic or systolic volume of right or left ventricle, left and right ventricular pressure, blood volume, pulmonary artery pressure and stroke volume can be obtained. Qualitative and quantitative agreement with the Starling preparation has been achieved for a 120 sec simulation time. We have also simulated pathological situations such as left ventricular failure, mitral stenosis, aortic valvular stenosis, hypertension, pulmonic valve stenosis adjusting the parameters of the circuit components.
\end{abstract}

\section{Introduction}

Mathematical models are powerful tools for investigating and understanding complex systems. Several models for the cardiovascular system have been proposed in the past which enhance knowledge about cardiovascular physiology $[1,2]$. These models provide understanding of the underlying mechanisms for normal conditions and diseases of the cardiovascular system such as arrhythmia [3], ischemia and hypertension [4] and permit exploitation of several therapy strategies [4]. Some of those models are based on electronic circuits $[3,5]$.

Electronic circuits are used for two purposes: (a) to study wave propagation when an excitation is taking place in the heart [6], (b) to model the cardiovascular system under normal conditions [7-11]. Modeling of cardiovascular diseases has been achieved using complicated models which are based on the solution of complex systems of equations $[4,12]$ and not electronic circuits.

It is the aim of our work to address simulation of the cardiovascular system using an electronic circuit under normal and pathological conditions. The principles of equivalent quantities have been used to design the circuit. Adjusting the parameters of the circuit components we have simulated diseases of the cardiovascular system. More specifically, we present simulation of mitral valve stenosis, triscupid valve stenosis, pulmonic valve stenosis, aortic valve stenosis, hypertension and changes in heart rate.

\section{Materials and methods}

The electronic circuit which is used for the simulation of the cardiovascular system is shown in Fig. 1. The design of the circuit is based on the principles of equivalent quantities as it is demonstrated in Table 1.

Table 1. Equivalent quantities.

\begin{tabular}{|l|l|l|}
\hline $\begin{array}{l}\text { Cardiovascular } \\
\text { System }\end{array}$ & $\begin{array}{l}\text { Electronic } \\
\text { Circuit }\end{array}$ & $\begin{array}{l}\text { Equivalence } \\
\text { Relations }\end{array}$ \\
\hline Voltage & Pressure & $1 \mathrm{~V} \leftrightarrow 10 \mathrm{mmHg}$ \\
\hline Current & Blood Flow & $1 \mu \mathrm{A} \leftrightarrow 100 \mathrm{ml} / \mathrm{sec}$ \\
\hline Resistance & Resistance & $1 \mathrm{M} \Omega \leftrightarrow 1 \mathrm{U}$ \\
\hline Capacitance & Capacitance & $1 \mu \mathrm{F} \leftrightarrow 100 \mathrm{ml} / 10 \mathrm{mmg}$ \\
\hline Charge & Volume & $1 \mu \mathrm{As} \leftrightarrow 100 \mathrm{ml}$ \\
\hline
\end{tabular}

In the design of the circuit we have taken into account the Starling law of the heart [1,2], which states that within physiological limits the heart pumps all the blood that returns to it without undue damming of blood in the veins. In addition, we assumed that the inertia of the blood is ignored and the left and right ventricular have the same capacitance. The circuit consists of three parts as the cardiovascular system: the heart (ventricle and atrium), the pulmonary circuit and the systemic circuit. The capacitance ratio between systemic and pulmonary circuit is approximately $1 / 7$ and between systemic arterial and systemic venous about $1 / 40$.

A pacemaker is connected in the circuit to drive the 
two ventricles. The pacemaker is a square wave generator with adjustable frequency. The pacemaker operates in $1 \mathrm{~Hz}$ frequency with duration of systole and diastole 0.25 and $0.75 \mathrm{sec}$, respectively. The A-V valves are simulated by a voltage-controlled switch and a $20 \mathrm{k} \Omega$ resistor. When the A-V valves are open, the switch is "on" and as the result the ventricles are "off" simulating diastole phase. The outflow tract valves (pulmonary, aortic) are simulated by diodes with adjustable internal parameters. The parameters of the cardiovascular system are measured in several points of the circuit. These points correspond to circles in Fig. 1.

The circuit must be modified to be used for the simulation of cardiovascular diseases. In our case, this can be achieved adjusting parameters of the circuit components.
To simulate mitral stenosis we use an adjustable resistor outside the mitral valve and two time-controlled switches. When the simulation starts, a $60 \mathrm{~V}$ battery is used for $5 \mathrm{sec}$ to simulate the venous reservoir. Steady state is established in $16 \mathrm{sec}$. After $60 \mathrm{sec}$ a $1 \mathrm{M} \Omega$ resistor is connected to the circuit. Increasing the resistance we reduce the charge from the LA to the LV simulating the mechanism of the mitral stenosis [2]. Pulmonic valve stenosis and aortic valvular stenosis have also been simulated using similar procedures. Hypertension [1,2] is simulated increasing the resistance in small arteries of the systemic from $7.5 \mathrm{M} \Omega$ to $12 \mathrm{M} \Omega$. The $12 \mathrm{M} \Omega$ resistor replaces the $7.5 \mathrm{M} \Omega$ after $60 \mathrm{sec}$ of steady state simulation. We have also simulated hear rate changes adjusting the value of the pacemaker frequency.

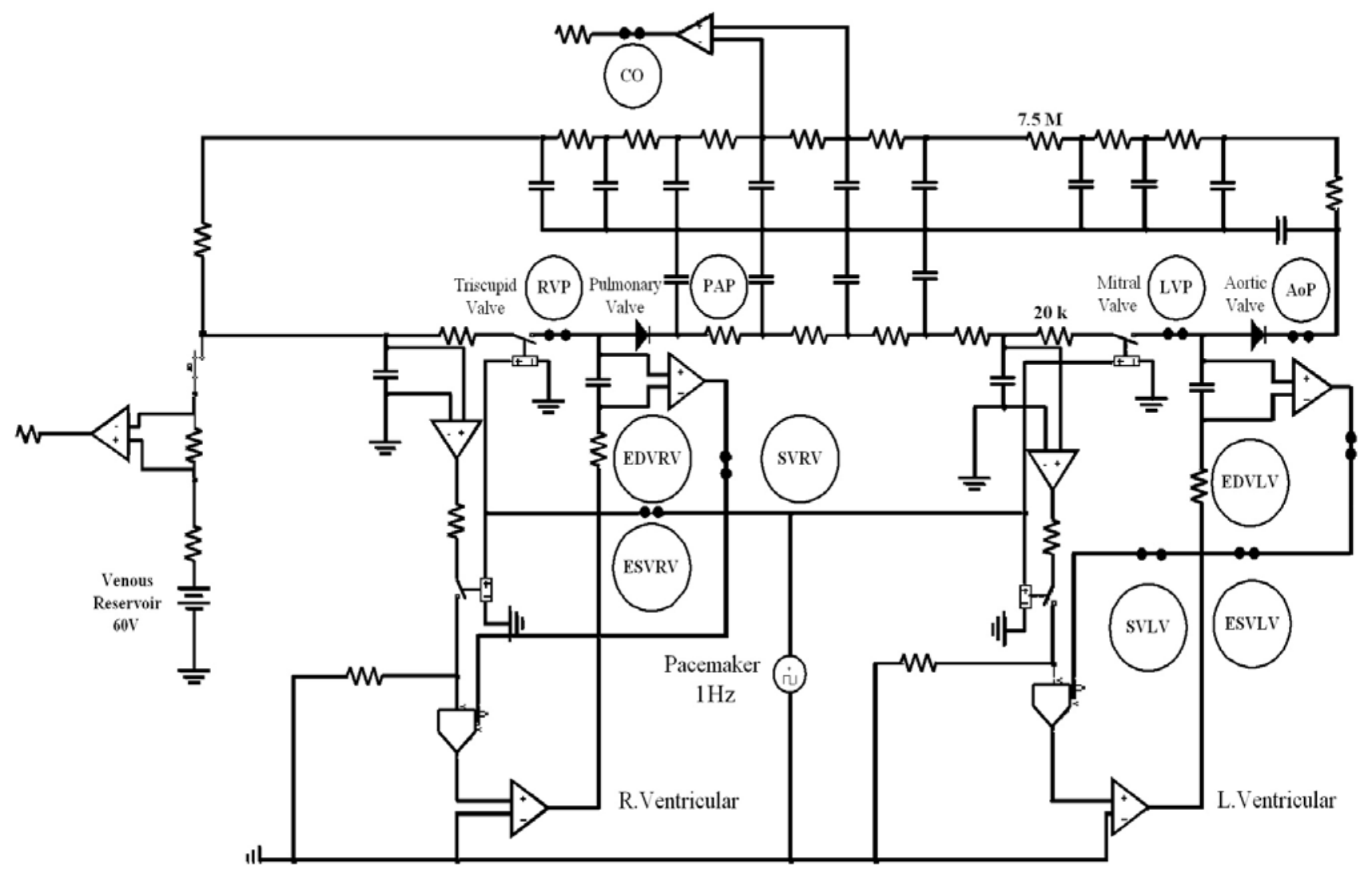

Figure 1. The proposed electronic circuit. 
Table 2. Results for normal condition, mitral stenosis, hypertension and hear rate increase.

\begin{tabular}{|c|c|c|c|c|}
\hline Measurements & Normal Conditions & Mitral Stenosis & Hypertension & $\begin{array}{l}\text { Heart rate increase } \\
(2 \mathrm{~Hz})\end{array}$ \\
\hline RVP & $29 \mathrm{mmHg}$ & $31 \mathrm{mmHg}$ & $28 \mathrm{mmHg}$ & $27.4 \mathrm{mmHg}$ \\
\hline LVP & $136 \mathrm{mmHg}$ & $137 \mathrm{mmHg}$ & $156.2 \mathrm{mmHg}$ & $130 \mathrm{mmHg}$ \\
\hline PAP & $23.3 / 14.3$ & $26 / 19$ & $22.3 / 14.3$ & $21.9 / 17$ \\
\hline LAtP & $6.29 \mathrm{mmHg}$ & $12 \mathrm{mmHg}$ & $6.5 \mathrm{mmHg}$ & $6.08 \mathrm{mmHg}$ \\
\hline RatP & $4.5 \mathrm{mmHg}$ & $4.2 \mathrm{mmHg}$ & $4.27 \mathrm{mmHg}$ & $3.98 \mathrm{mmHg}$ \\
\hline EDVLV & $5.4 \mathrm{mmHg}$ & $3.55 \mathrm{mmHg}$ & $5.7 \mathrm{mmHg}$ & $4.8 \mathrm{mmHg}$ \\
\hline ESVLV & $2.4 \mathrm{mmHg}$ & $1.05 \mathrm{mmHg}$ & $2.9 \mathrm{mmHg}$ & $2.8 \mathrm{mmHg}$ \\
\hline SVLV & $3 \mathrm{mmHg} \leftrightarrow 450 \mathrm{ml} / \mathrm{min}$ & $2.5 \mathrm{mmHg} \leftrightarrow 375 \mathrm{ml} / \mathrm{min}$ & $2.8 \mathrm{mmHg} \leftrightarrow 420 \mathrm{ml} / \mathrm{min}$ & $2 \mathrm{mmHg} \leftrightarrow 300 \mathrm{ml} / \mathrm{min}$ \\
\hline EDVRV & $3.80 \mathrm{mmHg}$ & $3.5 \mathrm{mmHg}$ & $3.6 \mathrm{mmHg}$ & $2.9 \mathrm{mmHg}$ \\
\hline ESVRV & $0.80 \mathrm{mmHg}$ & $1 \mathrm{mmHg}$ & $0.8 \mathrm{mmHg}$ & $0.9 \mathrm{mmHg}$ \\
\hline SVRV & $3 \mathrm{mmHg} \leftrightarrow 450 \mathrm{ml} / \mathrm{min}$ & $2.5 \mathrm{mmHg} \leftrightarrow 375 \mathrm{ml} / \mathrm{min}$ & $2.8 \mathrm{mmHg} \leftrightarrow 420 \mathrm{ml} / \mathrm{min}$ & $2 \mathrm{mmHg} \leftrightarrow 300 \mathrm{ml} / \mathrm{min}$ \\
\hline $\mathrm{CO}$ & $4650 \mathrm{ml} / \mathrm{min}$ & $3675 \mathrm{ml} / \mathrm{min}$ & $4050 \mathrm{ml} / \mathrm{min}$ & $5150 \mathrm{ml} / \mathrm{min}$ \\
\hline AoP & $130 / 79 \mathrm{mmHg}$ & $129 / 65 \mathrm{mmHg}$ & $152.5 / 102.5 \mathrm{mmHg}$ & $125 / 95 \mathrm{mmHg}$ \\
\hline
\end{tabular}

\section{Results}

Results for the cardiovascular system under normal conditions, with mitral stenosis, with hypertension and with changes in heart rate are presented in Table 2. A list of all abbreviations used is provided in Appendix A. The results for normal conditions are similar to those reported in the literature for the cardiovascular system (Table 3). A remarkable increase of the AoP (15.25/10.25) and LVP (156 $\mathrm{mmHg}$ ) is observed in hypertension when the resistance in capillaries increases by $50 \%$. CO increases $(10.75 \%)$ when the HR increases from 1 to $2 \mathrm{~Hz}$ without changing the systole time of ventricles $0.25 \mathrm{sec}$. $\mathrm{CO}$ reaches the maximum value when $\mathrm{HR}=2 \mathrm{~Hz}$. A decrease in $\mathrm{CO}$ is observed for $\mathrm{HR}>2 \mathrm{~Hz}$, which agrees with the observation described in $[1,2]$. In the case of mitral stenosis we obtain: LatP $=12 \mathrm{mmHg}$, SVLV $=2,5 \mathrm{mmHg}(375 \mathrm{ml} / \mathrm{min}), \mathrm{CO}=24.5 \mathrm{mmHg}$ $(3675 \mathrm{ml} / \mathrm{min}$ ) and AoP 12.9/6.5 which are close to those reported in literature $[1,2]$.

\section{Discussion}

We have designed an analog circuit, which is able to simulate normal condition and diseases of the cardiovascular system. The measurements we obtain for mitral stenosis are close to what is reported in the literature: increase of the LatP $(50 \%)$, significant decrease of the SVLV (16\%) and reduced the CO (26\%) $[2,13]$.

Our model is advantageous compared to other models since it requires only fundamental knowledge in the design of electronic circuits $[14,15]$ and does not involve complex equations. Compared to other electronic circuit models it is also advantageous since both normal conditions and diseases of the cardiovascular system can be simulated. The proposed model can be further upgraded to achieve more accurate simulations with fewer assumptions simply modifying the diastole time, systole time and the capacitance of LV and RV.

Table 3. Comparison of simulation results in normal condition vs physiological measurements of the cardiovascular system.

\begin{tabular}{|l|c|c|}
\hline Quantity & $\begin{array}{c}\text { Physiological } \\
\text { Measurements }\end{array}$ & Simulation \\
\hline RVP & $25-30 \mathrm{mmHg}$ & $29 \mathrm{mmHg}$ \\
\hline LVP & $120-130 \mathrm{mmHg}$ & $136 \mathrm{mmHg}$ \\
\hline PAP & $21-25 / 7-13$ & $23.3 / 14.3$ \\
\hline LAtP & $7-8 \mathrm{mmHg}$ & $6.29 \mathrm{mmHg}$ \\
\hline RatP & $4-6 \mathrm{mmHg}$ & $4.5 \mathrm{mmHg}$ \\
\hline CO & $5000 \mathrm{ml} / \mathrm{min}$ & $4650 \mathrm{ml} / \mathrm{min}$ \\
\hline AoP & $120-130 / 80-90 \mathrm{mmHg}$ & $130 / 79 \mathrm{mmHg}$ \\
\hline
\end{tabular}

\section{Conclusions}

We have developed electronic circuits to simulate the behavior of the cardiovascular system under normal and pathological conditions using the concept of the equivalent quantities. A circuit similar to human cardiovascular system with two ventricles separated from the systemic and the pulmonary circulation has been implemented. Assuming that the capacitance of the LV and RV is the same the simulation for $120 \mathrm{sec}$ ( total 
charge is circulated once through the system within 60 sec) of the normal conditions and several diseases of the cardiovascular system provided with results which are very close to those reported in the literature. Further upgrade of the circuit is possible to explain more complicated mechanisms causing disorders of the cardiovascular system.

\section{Appendix A}

\section{Table 3. List of Abbreviations}

$\begin{array}{ll}\text { Aortic pressure } & \text { AoP } \\ \text { Atrio-ventricular valve } & \text { A-V valve } \\ \text { Atrial pressure } & \text { AtP } \\ \text { Cardiac output } & \text { CO } \\ \text { Stroke volume } & \text { SV } \\ \text { Ventriculo-aortic valve } & \text { V-Ao valve } \\ \text { Blood volume } & \text { BV } \\ \text { End-diastolic volume of right ventricle } & \text { EDVRV } \\ \text { End-diastolic volume of left ventricle } & \text { EDVLV } \\ \text { Ejection fraction of the right ventricle } & \text { EFRV } \\ \text { Ejection fraction of the left ventricle } & \text { EFLV } \\ \text { End-systolic volume of left ventricle } & \text { ESVLV } \\ \text { End-systolic volume of right ventricle } & \text { ESVRV } \\ \text { Left ventricle } & \text { LV } \\ \text { Left ventricular pressure } & \text { LVP } \\ \text { Left atrial pressure } & \text { LatP } \\ \text { Pulmonary artery pressure } & \text { PAP } \\ \text { Right atrial pressure } & \text { RatP } \\ \text { Right ventricle } & \text { RV } \\ \text { Right ventricular pressure } & \text { RVP } \\ \text { Stroke volume of the right ventricle } & \text { SVRV } \\ \text { Stroke volume of the left ventricle } & \text { SVLV } \\ \text { Aortic pressure } & \text { AoP } \\ \text { Atrio-ventricular valve } & \text { A-V valve } \\ \text { Atrial pressure } & \text { AtP }\end{array}$

\section{References}

[1] Sideris DA. Primary Cardiology. Athens: Scientific Editions Grigorios Parisianos, 1991 (in Greek).

[2] Guyton AC, Hall JE. Textbook of medical physiology. New York. Saunders Editions, 1996.

[3] Glass L, Hunter P, McCulloch A. Theory of the Heart: Biomechanics, Biophysics and Nonlinear Dynamics of Cardiac Function. Springer-Verlag, New York, 1991.

[4] Li X, Bai J, Cui S, Wang S. Simulation study of the cardiovascular functional status in hypertensive situation. Computers in Biology and Medicine 2002;2:345-362.

[5] Draguhn A, Pfeiffer M, Heinemann U. Polder R. A simple hardware model for the direct observation of voltageclamp performance under realistic conditions. Journal of Neuroscience Methods 1997;78:105-113.

[6] Riemer LT, Tung L. Focal extracellular potential: A means to monitor electrical activity in single cardiac myocytes. Am J Physiol Heart Circ Physiol 2000;278:H1383-H1394.

[7] Pondar T, Runove F, Kordas M. Simulation of cardiovascular physiology: The diastolic function(s) of the heart. Computers in Biology and Medicine 2002;32:363377.

[8] Kordas M. Analysis of a simplified electrical analog of circulation. Med Biol Eng 1968;6:109-114.

[9] Pickering WD, Nikiforuk PN, Merriman JE. Analogue computer model of the human cardiovascular control system. Med. \& Biol. Eng 1969; vol 7:401-410.

[10] Kordas M, Trontelj J, Leonardis S. An electrical model of blood circulation. Med. Biol. Eng 1968;6:449-451.

[11] Shau C, Wu CR. Analog transmission line model for simulation of systemic circulation. IEEE Trans Bio Eng 1997:90-94.

[12] Mukkamala R, Cohen R. A Forward model based validation of cardiovascular system identification. Am J Physiology Heart Circ Physiol 2001;281:H2714-H2730.

[13] Rupnik M, Runovc F, Sket D, Kordas M. Cardiovascular Physiology: simulation of steady state and transient phenomena by using the equivalent electronic circuit. Computer Methods and Programs in Biomedicine 2002;67:1-12.

[14] Sedra A. Microelectronic circuits. Saunders College Publishing, 1991.

[15] Malvino. Electronic principles.The McGraw-Hill Companies Inc, $6^{\text {th }}$ edition, 1999.

[16] Shivakumar PN, Chi-Sing Man, Rabkin S. Modeling of the Heart and pericardium at end-diastole. J. Biomechanics. 1989; vol 22:201-209.

Address for correspondence.

Dimitrios Fotiadis.

Unit of Medical Technology and Intelligent Information Systems, Dept. of Computer Science, University of Ioannina, GR 45110, Ioannina, Greece.

fotiadis@cs.uoi.gr 